\title{
NASA Systems Analysis and Concepts Directorate Mission and Trade Study Analysis
}

\author{
Wendell Ricks*, Mark Guynn ${ }^{\dagger}$, Andrew Hahn ${ }^{\ddagger}$, Roger Lepsch ${ }^{\S}$, and Dan Mazanek ${ }^{* *}$ \\ NASA Langley Research Center, Hampton, Virginia 23681 \\ Sam Dollyhigh ${ }^{\dagger \dagger}$ \\ Swales Aerospace, Hampton, Virginia 23681
}

\begin{abstract}
Mission analysis, as practiced by the NASA Langley Research Center's Systems Analysis and Concepts Directorate (SACD), consists of activities used to define, assess, and evaluate a wide spectrum of aerospace systems for given requirements. The missions for these systems encompass a broad range from aviation to space exploration. The customer, who is usually another NASA organization or another government agency, often predefines the mission. Once a mission is defined, the goals and objectives that the system will need to meet are delineated and quantified. A number of alternative systems are then typically developed and assessed relative to these goals and objectives. This is done in order to determine the most favorable design approaches for further refinement. Trade studies are performed in order to understand the impact of a requirement on each system and to select among competing design options. Items varied in trade studies typically include: design variables or design constraints; technology and subsystem options; and operational approaches. The results of trade studies are often used to refine the mission and system requirements. SACD studies have been integral to the decision processes of many organizations for decades. Many recent examples of SACD mission and trade study analyses illustrate their excellence and influence. The SACD-led, Agency-wide effort to analyze a broad range of future human lunar exploration scenarios for NASA's Exploration Systems Mission Directorate (ESMD) and the Mars airplane design study in support of the Aerial Regional-scale Environment Survey of Mars (ARES) mission are two such examples. This paper describes SACD's mission and trade study analysis activities in general and presents the lunar exploration and Mars airplane studies as examples of type of work performed by the SACD.
\end{abstract}

\section{Introduction}

NASA Langley Research Center's Systems Analysis and Concepts Directorate (SACD) mission analysis activities follow the Doctrine of Successive Refinement (Fig. 1) as discussed in the NASA Systems Engineering Handbook. ${ }^{1}$ This process begins with mission definition. Once a mission is defined, the goals and objectives (requirements) that the system will need to meet are delineated and quantified. A number of alternative systems are then typically developed and assessed relative to these goals and objectives. This is done in order to refine the requirements and to provide scope when determining the most favorable design approaches for further refinement. SACD trade studies are typically performed to understand the impact of the mission requirements on each system in order to select among competing design options and identify technology challenges. Items varied in trade studies typically include: design variables or design constraints such as cargo weight, range, and number of crew; technology and subsystem options; and operational approaches. The results of trade studies are also used to refine the mission and system requirements. When analyses for a system are performed beyond the early conceptual phases, the increased levels of detail and analysis resolution allow for further in-depth mission analysis and trade

\footnotetext{
* Aeronautical Systems Analysis Manager, Systems Analysis and Concepts Directorate, M/S 449, Member AIAA

${ }^{\dagger}$ Aerospace Engineer, Aeronautics Systems Analysis Branch, M/S 442, Senior Member AIAA

₹ Aerospace Engineer, Aeronautics Systems Analysis Branch, M/S 442,

$\S$, Vehicle Analysis Branch, M/S 451,

*** Aerospace Engineer, Space Mission Analysis Branch, M/S 462, Member AIAA

${ }^{\dagger+}$ Aerospace Engineer, NASA Langley Research Center, M/S 442, Associate Fellow AIAA
} 
studies to refine the systems. This general approach is an integral part of the systems engineering process where the design decisions made during the course of a project's development must be traceable to the results of analyses.

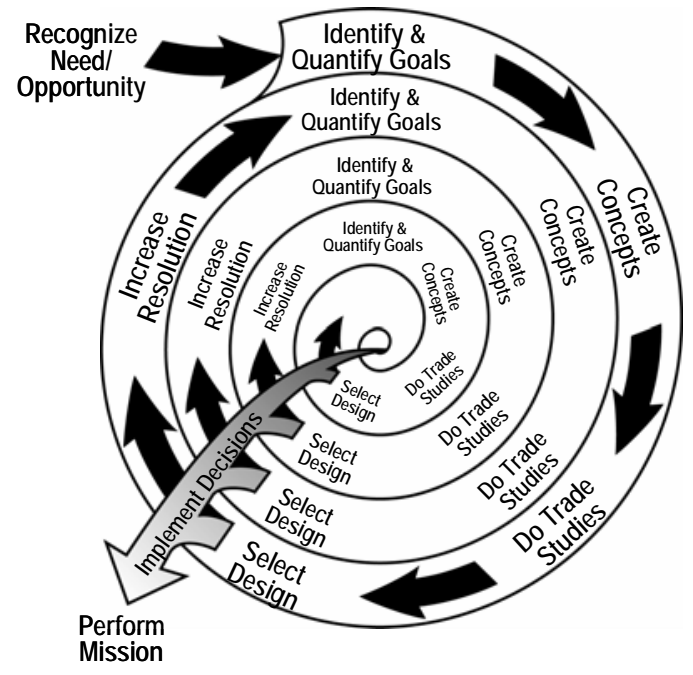

Figure 1. The Doctrine of Successive Refinement.

Many organizations that perform mission analyses and trade studies tend to work in narrowly defined areas. NASA, and the other organizations and agencies that the SACD serves, have analytical needs that span an incredibly wide range of concepts and architectures and involve many disciplines. These disciplines include physics-based ones such as aerodynamics, propulsion, flight mechanics, and structures; and non physics-based ones such as cost, reliability, safety, and operations. Depending on the level of analysis fidelity applied in a system definition activity, a multidisciplinary analysis can be performed by only a few people having broad, systems-level experience or by a larger team consisting of individual discipline experts.

The type of analysis that is performed is often dictated by the current design phase of a project or study and by time constraints. Short, investigative studies often necessitate the use of a small team using quick-running, highlevel (highly abstract) tools; whereas in-depth studies or system refinement activities often involve larger teams utilizing more accurate and more computationally intensive tools. Although access to a broad range of analytical tools is important, the expertise and experience of the analysts is vital. Interdependencies and interactions between disciplines are extensive in the design of aerospace systems, so the analysis is highly complex for both short and indepth studies. The ability of the analysts to understand the problem, formulate a plan, acquire and learn new tools, modify existing tools as needed, and satisfy the customer's requirements within scope and time limitations, usually on concepts in which there is little prior experience, is the SACD's greatest asset.

By the nature of NASA's research and development activities, the SACD mission and trade study analyses are focused on pushing the state-of-the-art in both developing advanced methodologies and applications to advanced concepts (e.g., vehicle designs). Often the advanced concepts under study are unique as a result of applying emerging technologies. These concepts, such as a solar/regenerative fuel cell powered Un-inhabited Air Vehicle (UAV) require new methods for design and analysis. Once developed both the methodology and study results are often supplied to industry and academia.

All of the mission and trade study analyses at NASA Langley are conducted within a framework to assure quality of the methods and study output. As with all research at Langley, the processes by which analysis is undertaken and conducted are specified in the ISO-9001 certified Langley Management System. The SACD's analysis methods and techniques have been commended highly in periodic formal peer reviews with experts from academia, industry, and other government agencies. However, the best indicator of the quality of SACD mission and trade study analysis is the numerous requests for study collaboration and methods. For example, the primary airplane synthesis and mission performance tool developed by Langley, the FLight OPtimization System (FLOPS), has a user community of over 200 organizations in 8 countries. The Langley developed spacecraft trajectory program, POST (Program to Optimize Simulated Trajectories), is widely used throughout the US (not disseminated outside the country due to ITAR restrictions).

SACD studies have been integral to the decision processes of many organizations for decades. Many recent examples of the SACD mission and trade study analyses illustrate their excellence and influence. An outstanding 
example is the world record setting, Mach 10, X-43A. The SACD performed the systems analysis for the Hyper-X Program, which resulted in the successful flight test of two, sub-scale scramjet powered vehicles. Two other examples are the SACD-led, Agency-wide effort to analyze a broad range of future human lunar exploration scenarios for NASA's Exploration Systems Mission Directorate (ESMD) and a Mars airplane design study in support of the Aerial Regional-scale Environment Survey of Mars (ARES). These two examples are discussed below.

\section{Human Lunar Exploration Scenarios}

In the spring of 2004 NASA's Exploration Systems Mission Directorate tasked the Langley Research Center to lead an Agency-wide team in analyzing a broad range of future human lunar exploration scenarios. The focus of this study was to perform assessments on a wide range of potential architectures and technological implementations in support of the Vision for Space Exploration announced by the President on January 14, 2004. Emphasis was placed on a "breadth" of transportation trade options while providing sufficient "depth" of analysis to identify unique performance, risk/reliability, and affordability differences among the trade options. This analysis identified and provided technical rationale for potentially feasible trade options as well as those that do not appear to be feasible. Additionally, systems analysis was conducted that identified capabilities required in the next 10-15 years. Only a summary of the study is presented here; see Ref. 2 for the complete set of assumptions and results.

Two broad lunar mission scenarios were investigated, both of which would permit NASA to conduct a wide range of scientific investigations and system and operational testing to reduce the risks of future human exploration of Mars. These lunar mission scenarios were defined as follows:

Lunar Mission Scenario \#1 (LMS-1): Enable global access for human exploration of the lunar surface via 7-day (surface duration) missions to multiple sites. Crews will conduct a wide range of scientific investigations and system and operational testing to reduce the risks of future human exploration of Mars. No pre-deployment of surface habitation facilities is permitted. A crew of four will travel to the moon with all crewmembers going to the lunar surface.

Lunar Mission Scenario \#2 (LMS-2): Enable human exploration missions to the moon's south polar region via multiple 30-90 day (surface duration) missions to a single site. Crews will conduct a wide range of scientific investigations and system and operational testing to reduce the risks of future human exploration of Mars. Pre-deployment of surface habitat facilities is permitted. A crew of four will travel to the moon with all crewmembers going to the lunar surface.

An LMS trade space (Fig. 2) was defined which identified options for orbital operations and Earth-moon transit; lunar descent; lunar ascent; and Earth entry, descent, and landing. Options for vehicle elements for each mission phase were also included in the LMS trade space.

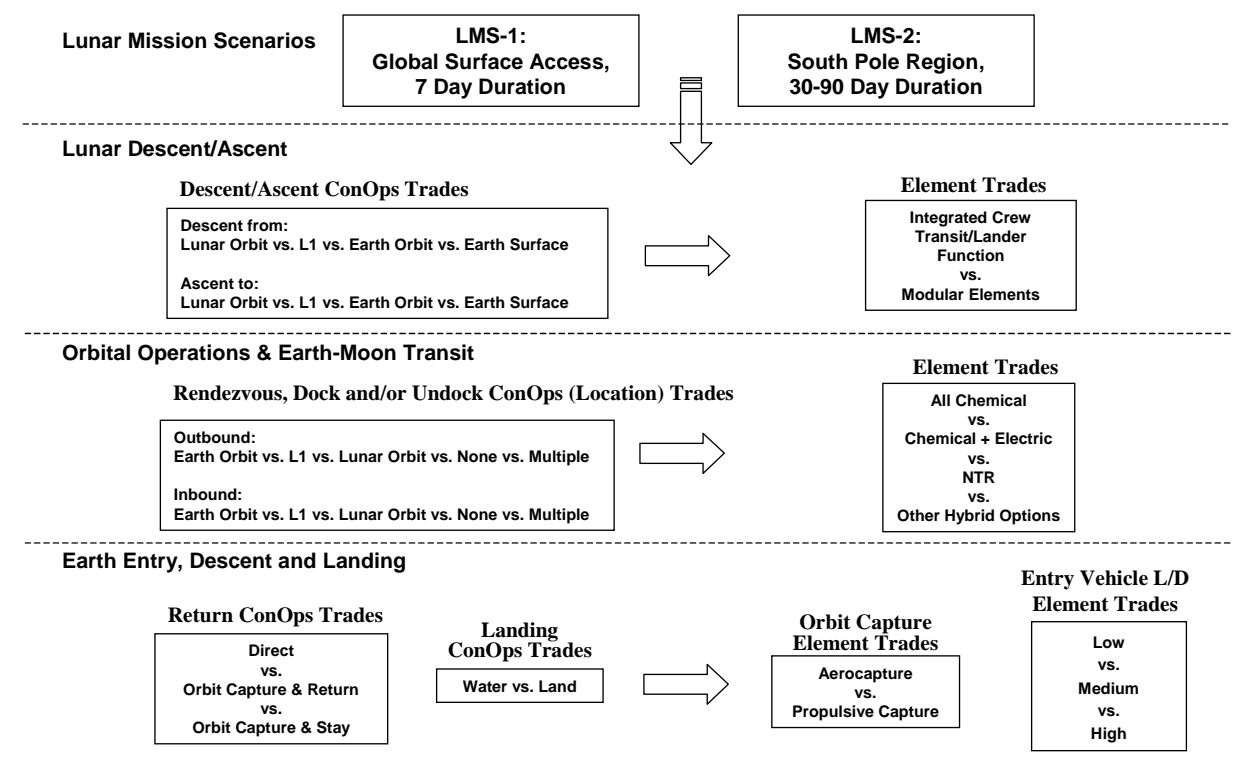

Figure 2. Lunar Mission Scenario functional trade space.

American Institute of Aeronautics and Astronautics 
Assessments were performed by:

- Defining a design reference mission (DRM) from the LMS trade space for each scenario (see Fig. 3 for the LMS-2 DRM),

- Using the DRM as a reference for comparison with other potential mission implementation concepts (referred to as trade options), and

- Evaluating and comparing figures of merit (top-level categories are safety/reliability; effectiveness and evolvability; development risk and schedule; and affordability) for the DRM and selected trade options.

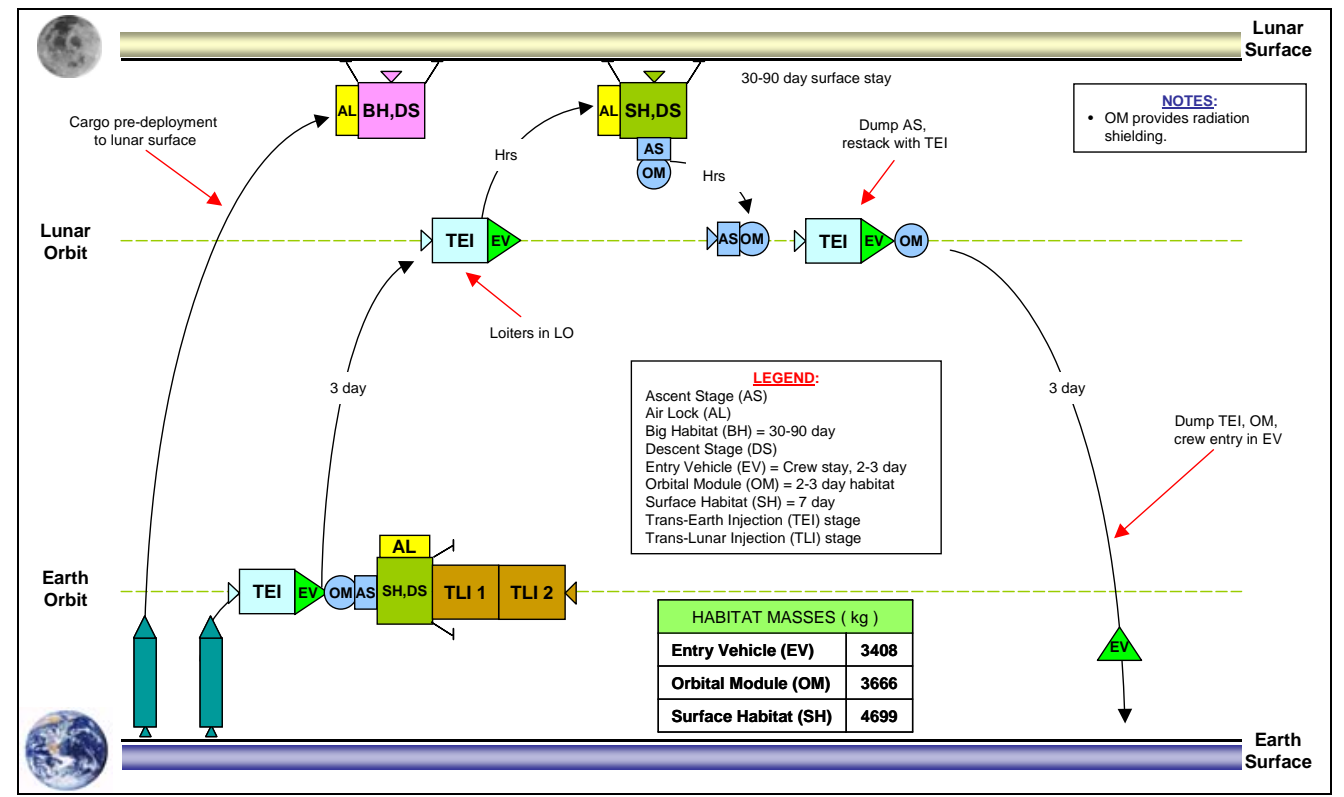

Figure 3. Lunar Mission Scenario-2 design reference mission profile.

Global trades (i.e., paradigm changing or critical infrastructure trades) for the trade options were identified and evaluated. These included in-situ resource utilization (ISRU) to generate lunar ascent propellant, pre-deployment or post-deployment of surface cargo, launch vehicle capability trades, mission control operations trades, communication and navigation infrastructure options, and element reusability trades.

An initial down selection of major trade tree branches was performed to establish data and rationale for potentially infeasible mission concepts and to provide focus on trade options to be analyzed in more detail. Ten trade options plus alternatives were analyzed for LMS-1 (see Table 1); thirteen trade options plus alternatives were analyzed for LMS-2 (see Table 2). 
Table 1. LMS-1 Trade Options

\begin{tabular}{|c|c|c|c|c|c|c|c|c|}
\hline \multirow[b]{2}{*}{$\begin{array}{l}\text { Trade } \\
\text { Option }\end{array}$} & \multicolumn{3}{|c|}{$\begin{array}{l}\text { Outbound from } \\
\text { Earth Surface }\end{array}$} & \multicolumn{4}{|c|}{$\begin{array}{l}\text { Inbound from } \\
\text { Lunar Surface }\end{array}$} & \multirow[b]{2}{*}{ Comments } \\
\hline & $\overrightarrow{5}$ & 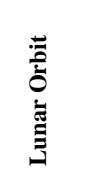 & 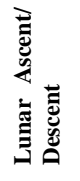 & 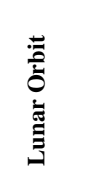 & $\exists$ & 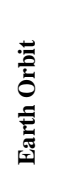 & 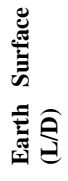 & \\
\hline $\begin{array}{c}\text { Option } 1 \\
\text { (DRM) }\end{array}$ & Chem & & Mod & & Chem & & Low & \\
\hline Option 2 & & Chem & Mod & Chem & & & Low & Same as Option 1 except through Lunar Orbit (LO). \\
\hline Option 3 & Chem $^{1}$ & Chem $^{2}$ & Mod & Chem & & & Low & $\begin{array}{l}\text { 1. TEI Stage performs Lunar flyby with landing segment, then } \\
\text { continues to } \mathrm{L}_{1} \text {. TEI rendezvous with crew in LO for return. } \\
\text { 2. Hab modules and landing stages capture in LO then descend } \\
\text { to Lunar surface. }\end{array}$ \\
\hline Option 4a & $\begin{array}{c}\text { Chem }+ \\
\text { Elec }\end{array}$ & & Mod & & $\begin{array}{c}\text { Chem + } \\
\text { Elec }\end{array}$ & & Low & $\begin{array}{l}\text { Same as Option } 1 \text { but using SEP to pre-deploy Lunar } \\
\text { Lander/Habitat at } \mathrm{L}_{1} \text {. }\end{array}$ \\
\hline Option 4b & & $\begin{array}{c}\text { Chem + } \\
\text { Elec }\end{array}$ & Mod & $\begin{array}{c}\text { Chem }+ \\
\text { Elec }\end{array}$ & & & Low & $\begin{array}{l}\text { Same as Option } 2 \text { but using SEP to pre-deploy Lunar } \\
\text { Lander/Habitat in LO. }\end{array}$ \\
\hline Option 4c & $\begin{array}{c}\text { Chem }+ \\
\text { Elec }\end{array}$ & & Mod & & $\begin{array}{c}\text { Chem + } \\
\text { Elec }\end{array}$ & & Low & $\begin{array}{l}\text { Same as Option } 1 \text { but using NEP to pre-deploy Lunar } \\
\text { Lander/Habitat at } \mathrm{L}_{1} \text {. }\end{array}$ \\
\hline Option 4d & & $\begin{array}{c}\text { Chem }+ \\
\text { Elec }\end{array}$ & Mod & $\begin{array}{c}\text { Chem }+ \\
\text { Elec }\end{array}$ & & & Low & $\begin{array}{l}\text { Same as Option } 2 \text { but using NEP to pre-deploy Lunar } \\
\text { Lander/Habitat in LO. }\end{array}$ \\
\hline Option 5a & NTR & & Mod & & NTR & & Low & NTR used for outbound and inbound legs. \\
\hline Option 5b & & NTR & Mod & NTR & & & Low & Single drop tank NTR used for outbound and inbound legs. \\
\hline Option 6a & Chem & & Mod & & Chem & Aero & Low & Same as Option 1 but with aerocapture at Earth return. \\
\hline Option 6b & & Chem & Mod & Chem & & Aero & Low & Same as Option 2 but with aerocapture at Earth return. \\
\hline Option 7a & Chem & & Mod & & Chem & Prop & Low & Same as Option 1 but with propulsive capture at Earth return. \\
\hline Option 7b & & Chem & Mod & Chem & & Prop & Low & Same as Option 2 but with propulsive capture at Earth return. \\
\hline Option 8a & Chem & & Mod & & Chem & & Med & Same as Option 1 but with med. lift/drag (L/D) entry vehicle. \\
\hline Option 8b & & Chem & Mod & Chem & & & Med & Same as Option 2 but with med. L/D entry vehicle. \\
\hline Option 9a & Chem & & Mod & & Chem & & Low & No outbound LEO staging orbit; 2 launches direct to $\mathrm{L}_{1}$ \\
\hline Option10a & Chem & & Int & & Chem & & Low & Integrated Lander/Crew Vehicle through $\mathrm{L}_{1}$. \\
\hline Option10b & & Chem & Int & Chem & & & Low & Integrated Lander/Crew Vehicle SCM through LO. \\
\hline
\end{tabular}


Table 2. LMS-2 Trade Options.

\begin{tabular}{|c|c|c|c|c|c|c|c|c|}
\hline \multirow[b]{2}{*}{$\begin{array}{l}\text { Trade } \\
\text { Option }\end{array}$} & \multicolumn{3}{|c|}{$\begin{array}{l}\text { Outbound from } \\
\text { Earth Surface }\end{array}$} & \multicolumn{4}{|c|}{$\begin{array}{l}\text { Inbound from } \\
\text { Lunar Surface }\end{array}$} & \multirow[b]{2}{*}{ Comments } \\
\hline & ت & 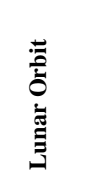 & 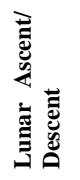 & 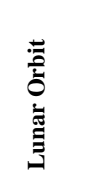 & 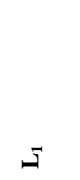 & 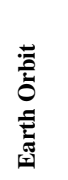 & 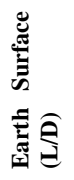 & \\
\hline $\begin{array}{l}\text { Option } 1 \\
\text { (DRM) }\end{array}$ & & Chem & Mod & Chem & & & Low & \\
\hline Option 2 & Chem & & Mod & & Chem & & Low & \\
\hline Option 3 & Chem $^{1}$ & Chem $^{2}$ & Mod & Chem & & & Low & $\begin{array}{l}\text { 1. TEI Stage performs Lunar flyby with landing segment, then } \\
\text { continues to } \mathrm{L}_{1} \text {. TEI rendezvous with crew in LO for return. } \\
\text { 2. Human landing segment captures in LO then descent to } \\
\text { Lunar surface. }\end{array}$ \\
\hline $\begin{array}{l}\text { Option } 4 \text { - } \\
\text { Human }\end{array}$ & & Chem & Mod & Chem & & & Low & \\
\hline $\begin{array}{l}\text { Option } 4- \\
\text { Lg. Hab }\end{array}$ & & Chem & & & & & Low & $\begin{array}{l}\text { Large habitat deployment to Lunar surface follows same path as } \\
\text { crew through Lunar orbit. }\end{array}$ \\
\hline $\begin{array}{l}\text { Option } 5 \text { - } \\
\text { Human }\end{array}$ & & $\begin{array}{c}\text { Chem }+ \\
\text { Elec }\end{array}$ & Mod & $\begin{array}{c}\text { Chem }+ \\
\text { Elec }\end{array}$ & & & Low & $\begin{array}{l}\text { Small habitat pre-deployed to Lunar orbit via electric } \\
\text { propulsion system. Human segment travels with EV and OM } \\
\text { modules using chemical propulsion. }\end{array}$ \\
\hline Option 6 & & NTR & Mod & NTR & & & Low & Single drop tank NTR for outbound and inbound legs. \\
\hline Option 7 & & Chem & Mod & Chem & & Aero & Low & Same as Option \#1 but with aerocapture at Earth. \\
\hline Option 8 & & Chem & Mod & Chem & & Prop & Low & Same as Option \#1 but with propulsive Earth capture. \\
\hline Option 9 & & & Mod & & & & Low & $\begin{array}{l}\text { Direct from Earth orbit to Lunar surface. EV + SH outbound; } \\
\text { EV only inbound. }\end{array}$ \\
\hline Option 10 & & Chem & Mod & Chem & & & Low & $\begin{array}{l}\text { No outbound LEO staging. } 3 \text { launches total with } 2 \text { for human } \\
\text { segment. }\end{array}$ \\
\hline Option 11 & Chem & & Mod & & Chem & & Low & $\begin{array}{l}\text { No outbound LEO staging. Similar to Option \#10 except } \\
\text { through } L_{1} \text { instead of Lunar orbit. }\end{array}$ \\
\hline Option 12 & & Chem & Mod & Chem & & & Med & Same as Option \#1 but with medium L/D entry vehicle. \\
\hline Option 13 & & & Int & & & & Low & 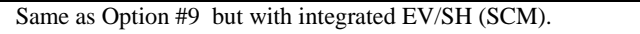 \\
\hline
\end{tabular}

Note: All trade options include pre-position of a large surface habitat module on the Lunar surface except Option \#4 in which the large surface habitat travels the same route as the crew. Options \#9 and \#13 travel direct from Earth orbit to the Lunar surface.

Legend: Chem - all chemical propulsion; Chem + Elec - chemical and electric (NEP, SEP) propulsion; NTR - Nuclear Thermal Rocket; Mod - modular elements; Aero - aerocapture in Earth orbit; Prop - propulsive capture in Earth orbit; SCM - single crew module; Outbound - Earth to Moon; Inbound - Moon to Earth.

\section{A. General Results}

The analysis for each LMS was performed independently and, therefore, treated as a separate mini-study. However, general trends in results of trade option analyses were observable across both lunar mission scenarios.

\section{Staging Location}

Staging from lunar orbit is preferable to staging from Earth-Moon $\mathrm{L}_{1}$ for both LMS-1 and LMS-2 trade options based on the following figures of merit: initial mass in low-Earth orbit (IMLEO) including habitat sizing; mission duration; abort options; time required to return crew to Earth in the event of a contingency; and mission risks and system hazards. This result is also valid when the transfer legs for the $\mathrm{L}_{1}$ trade options are optimized to minimize transfer time and IMLEO. Additionally, lunar orbit staging is more robust with respect to potential design and performance changes (sensitivities) than $\mathrm{L}_{1}$ staging, particularly with respect to incremental changes to lunar lander propellant mass fraction or specific impulse. That is, minor degradations in baseline specifications of lunar lander propellant mass fraction or specific impulse (and other design parameters) result in significantly greater increase in total mission IMLEO for $\mathrm{L}_{1}$ trade options than for lunar orbit trade options. Elements sized for lunar orbit staging may also have applications for other missions including $L_{1}$ science missions (e.g., telescope servicing) or Earth geostationary orbit missions (e.g., satellite deployment, servicing, and retrieval).

\section{Habitable Elements}

Several options for habitable elements were studied in LMS-1 and LMS-2 analyses: 
- One pressurized element consisting of the Earth Entry Vehicle/Transit/Lunar Surface Habitat (i.e., single crew module)

- Two elements including the Earth Entry Vehicle/Transit Element + Lunar Surface Habitat $(\mathrm{EV}+\mathrm{SH})$

- Three elements including the Earth Entry Vehicle + Orbital/Transit Module + Lunar Surface Habitat $(\mathrm{EV}+\mathrm{OM}+\mathrm{SH})$.

Analysis results show that three habitable elements are superior to one or two habitable elements considering the following figures of merit: IMLEO and IMLEO sensitivities, mission risks and system hazards, design redundancy, abort options, and applicability and evolvability of elements and operations of a lunar architecture to future Mars missions. The use of multiple habitable elements also facilitates functional partitioning. This allows more efficient grouping of common crew functions (e.g., exercise, medical/clinic, and human research) and separation of different functions (e.g., food preparation/galley and sleeping). Multiple habitable elements may increase crew safety by providing multiple "separable" pressurized volumes that may serve as independent safe havens if required. The additional costs associated with developing multiple elements may affect the attractiveness of this approach and should be assessed. This approach also has applicability to future Mars missions. For example, these elements may have common uses across both missions (e.g., the Entry Vehicle may be similar for both lunar and Mars missions) and/or may be scaleable at a system or subsystem level (e.g., scaling Lunar Surface Habitat or Orbital Module systems/subsystems when used for a Mars mission).

\section{Launch Vehicle Manifesting}

Preliminary manifesting analysis was performed to evaluate the number of launches required for a lunar mission as a function of launch vehicle payload capability between 25 and $100 \mathrm{t}$. This manifesting analysis was based on mass only; no volumetric layout assessments were performed. Liquid oxygen/hydrogen $\left(\mathrm{LOX} / \mathrm{LH}_{2}\right)$ propulsive systems were assumed as the baseline approach for all mission segments. Additionally, a two-segment trans-lunar injection (TLI) stage approach was assumed. From a mass perspective only, all elements studied in LMS-1 and LMS-2 can be accommodated, at least partially fueled, with a 25 t class launch vehicle. Further studies to address volumetric constraints and risk, safety, and affordability issues associated with on-orbit refueling need to be performed. The minimum launch vehicle capability necessary to launch crew only (consistent with the Level 1 exploration objective of separating crew from cargo for exploration mission launches to the greatest extent practical) is 10 to $13.5 \mathrm{t}$. This minimum capability provides a crew of 4 with the propulsive capability to return to Earth in the event of a mission abort after launch into Earth orbit. Many hardware elements needed for the lunar trade options analyzed could be launched with existing launch vehicles. Potential uses of existing launch vehicles include the early deployment and on-orbit testing of critical Project Constellation exploration systems.

\section{Safety and Reliability}

An initial analysis was performed to identify and evaluate abort options (per mission phase except launch to Earth orbit), mission risks, and system hazards for the primary trade options. A key finding was that operational abort requirements, which are currently undefined, should be established to allow for the representative evaluation of trade options from a safety and reliability standpoint. Additionally, further analysis - including assessment of probability of mission success and probability of loss of crew - is necessary to adequately distinguish between trade options considering safety and reliability. Specific mission risks and system hazards common across all trade options include: development and system complexity associated with $\mathrm{LOX} / \mathrm{LH}_{2}$ zero boil-off technology, development of highly throttle-able $\mathrm{LOX} / \mathrm{LH}_{2}$ engines, and radiation and micrometeoroid protection during transit to and from the moon and lunar surface stay.

\section{B. LMS-1 Results}

Assuming all-chemical propulsion with $\mathrm{LOX} / \mathrm{LH}_{2}$ propellants and reduced stage dry masses, an IMLEO of $136 \mathrm{t}$ (Fig. 4) is estimated using a lunar orbit staging approach, which matches the equivalent value for Apollo but delivers twice the number of crew onto the lunar surface (four) for roughly twice the stay time (7 days). For the all-chemical option, delivery to orbit of system elements is feasible using launch vehicles of $25 \mathrm{t}$ capacity (from a mass perspective only; no volumetric layout assessments were performed). As few as four launches can accommodate delivery of elements to LEO, but additional propellant launches are required to fuel the large TLI stages on orbit. Further studies to address volumetric constraints and risk, safety, and affordability issues associated with on-orbit refueling need to be performed. Alternately, fully fueled TLI stages can be delivered using a launch vehicle of $50 \mathrm{t}$ capacity. The application of higher performing nuclear thermal or electric propulsion systems result in substantial improvements in IMLEO. The best results are achieved with nuclear thermal rocket propulsion. All elements can be delivered to LEO together in a single launch of less than 100 t. However, a complete assessment considering development cost and schedule has not been performed. Crew size has a significant impact on IMLEO. Sensitivity 
results indicate that IMLEO increases or decreases by more than 25\% when crew size is increased to six or reduced to two.

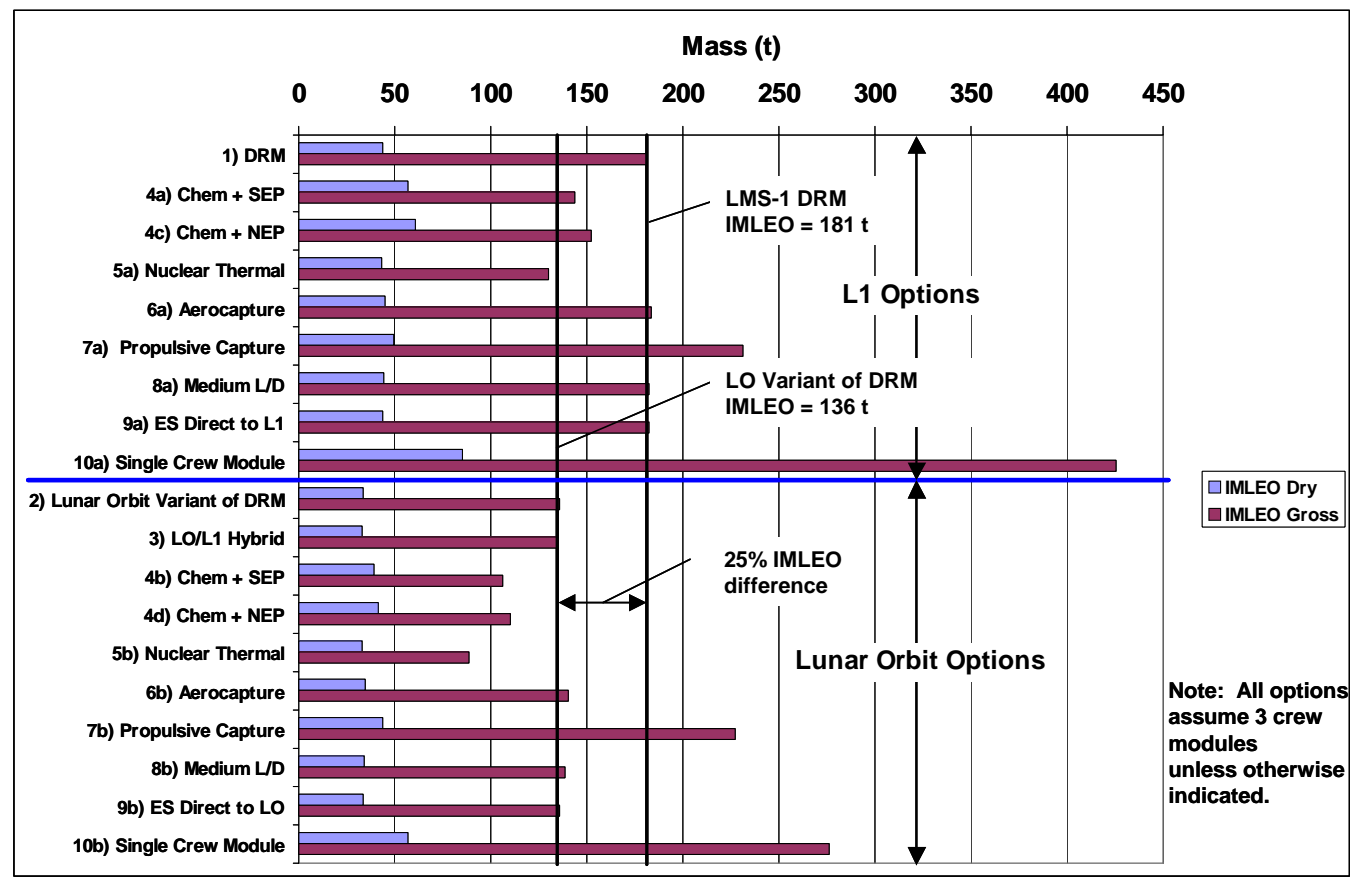

Figure 4. IMLEO for Lunar Mission Scenario-1 trade options.

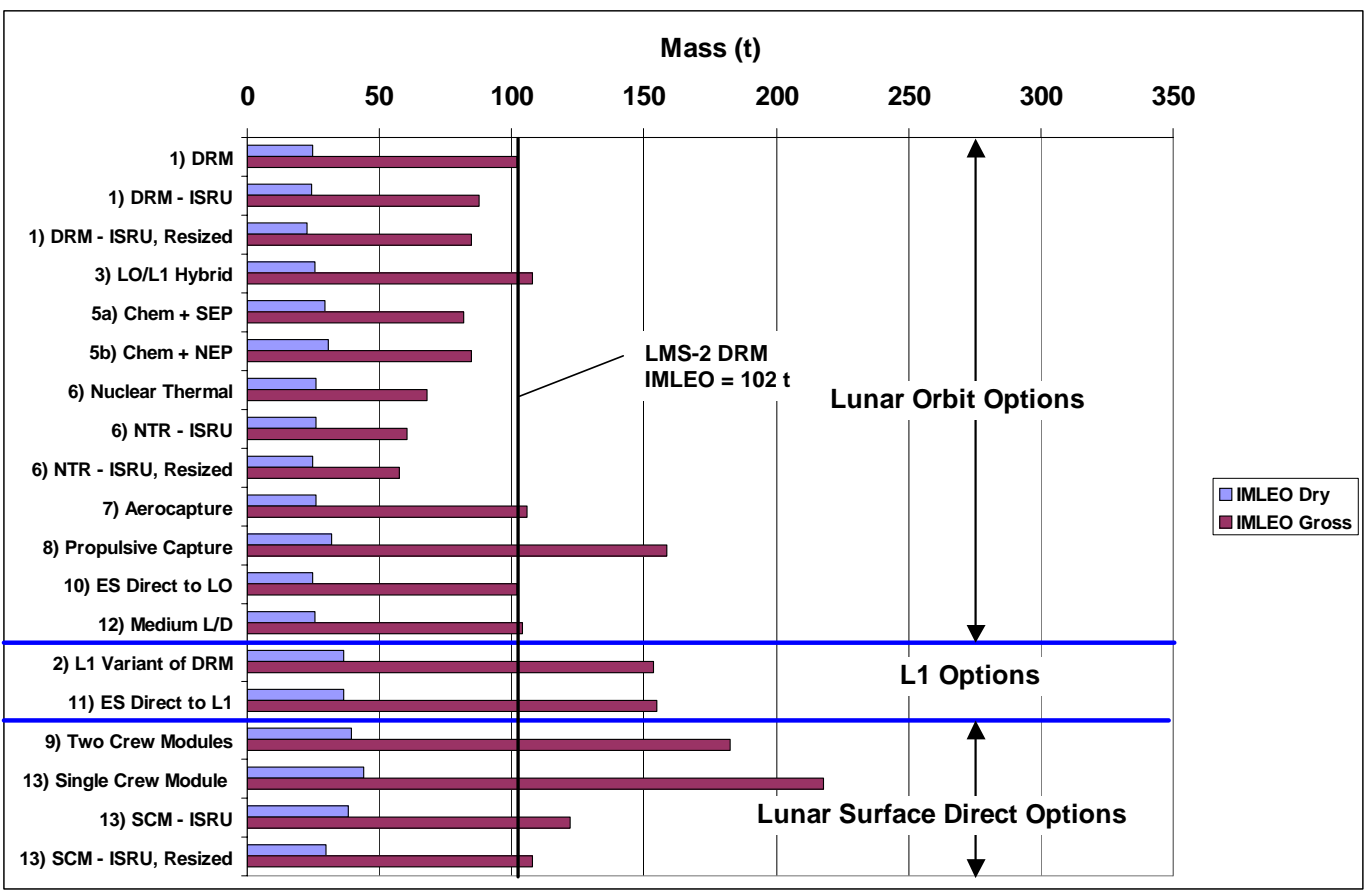

Note 1: All options assume 3 crew modules unless otherwise indicated.

Note 2: IMLEO values are for the human mission only; cargo mission IMLEO not included.

Note 3: IMLEO gross mass includes total vehicle dry mass and full propellant load.

Figure 5. IMLEO for Lunar Mission Scenario-2 trade options. 


\section{LMS-2 Results}

By limiting landing sites to the south pole region and pre-deploying a surface habitat, IMLEO associated with crew transfer to and from the lunar surface is substantially reduced (Fig. 5). An all-chemical approach using $\mathrm{LOX} / \mathrm{LH}_{2}$ propellants requires $102 \mathrm{t}$ IMLEO, a 25\% reduction from the equivalent option in LMS-1. However, to pre-deploy a fully supplied habitat for 30 days duration requires an additional IMLEO of $120 \mathrm{t}$ assuming $\mathrm{LOX} / \mathrm{LH}_{2}$ propulsion and a conventional, hard shell structure approach for the habitat. This mass increases to $285 \mathrm{t}$ for surface duration of 90 days. The application of higher performing propulsion for the pre-deployment or use of inflatable habitat technologies can potentially reduce mass significantly, but these options were not investigated since this study focused specifically on the crew transport mission. From a mass perspective only, it is feasible to launch all elements for a 30-day mission using a $25 \mathrm{t}$ capacity launch vehicle assuming some stages are fueling on-orbit, but the number of launches required to support this approach may be prohibitively high. As with LMS-1, the application of nuclear thermal and electric propulsion systems substantially improves IMLEO. For an NTR approach, the crew transfer portion of the mission can be accomplished for less than $70 \mathrm{t}$ IMLEO. In-situ resource utilization (ISRU) can have a significant impact in reducing mission IMLEO, but the overall cost, additional mass delivered, and mass payback period for the ISRU plant must be considered.

Additional mission risks and system hazards identified for LMS-2 resulting from the extended mission duration include:

- Development of precision landing capability that will allow the lunar descent vehicle to land within close proximity to a pre-deployed cargo vehicle already on the lunar surface

- Developing and equipping a long-term (30-90 day) habitat

- Physical and mental health of the crew during a 30-90 day mission on the lunar surface

- $\quad$ EVA suit damage caused by lunar dust

- Development of a $\mathrm{LOX} / \mathrm{LH}_{2}$ engine capable of reliable operation after a 30-90 day mission.

\section{Applicability of Lunar Systems/Elements to Future Mars Missions}

A primary objective of this study was to identify the potential application of lunar systems/elements to future Mars architectures. In the context of the LMS-1 and LMS-2 scenarios, the applications identified were:

- Selection of an analogous Mars concept of operations approach for the Moon would permit testing of techniques and systems with application for future Mars missions. For example, the IMLEO required for a Mars mission will likely require vehicle assembly in LEO.

- A minimal mass Earth Entry Vehicle would be desirable for a Mars mission, provided that entry issues can be addressed (e.g., thermal protection, entry velocity, etc.).

- Propellant tank designs for the lunar descent stage based on a heavy lift shroud size could have application for a Mars tank approach that would "wrap" tanks around habitats for increased radiation protection.

- An efficient NTR stage using clustered small engines is attractive for lunar missions. This may reduce IMLEO, the number of architecture elements, and the propellant penalty of large plane change maneuvers. A technology push in this area could support a stage development for CY2020 timeframe lunar missions. The same small, multi-functional engines could be used on a Mars transfer vehicle, eliminating the need for additional or new engine development efforts.

- High power electric propulsion (e.g., NEP, SEP) is on a spiral development path for Mars missions for both crew and cargo.

\section{Aerial Regional-scale Environment Survey}

In 2002 the Aerial Regional-scale Environmental Survey (ARES) mission was proposed as a NASA Mars Scout mission for launch in 2007. The objective of the proposed mission was to provide high-value science measurements in the areas of atmospheric chemistry, surface geology and mineralogy, and crustal magnetism. ${ }^{3}$ A key feature of the proposed mission was the use of an aerial vehicle as the science instrument platform. Aerial vehicles provide a unique capability for conducting science and exploration at Mars. The traditional wisdom for aircraft design does not always apply for this type of vehicle, however, and geometric, aerodynamic, and mission constraints result in a limited feasible design space. Designing a successful Mars airplane requires building an understanding of the design space and the relative importance of various design parameters and mission requirements. Trade studies provide a mechanism to build this understanding and were used extensively in the ARES airplane concept development. The concept development team encompassed a broad range of expertise across NASA (Langley, Ames, and Glenn Research Centers), industry (Aurora Flight Sciences), and academia (Stanford University and Massachusetts 
Institute of Technology). Major design trades conducted during the ARES concept development included: aeroshell packaging approach, propulsion approach, tail arrangement and geometry, and wing geometry. Because of the unique nature of Mars aircraft design, rigorous quantitative analyses were not possible for all the trade studies. Design decisions were informed with both qualitative evaluation and high-level quantitative analyses, focused on the most important parameters for the ARES mission. The result of this process was the Mars airplane concept illustrated in Fig. 6, which enables the high-value science objectives of the ARES mission to be accomplished while also fulfilling the desire for a simple, low-risk vehicle design. Highlights of the ARES airplane design evolution are presented below to illustrate the use of trade studies during concept design and development. A more detailed discussion can be found in Ref. 4.

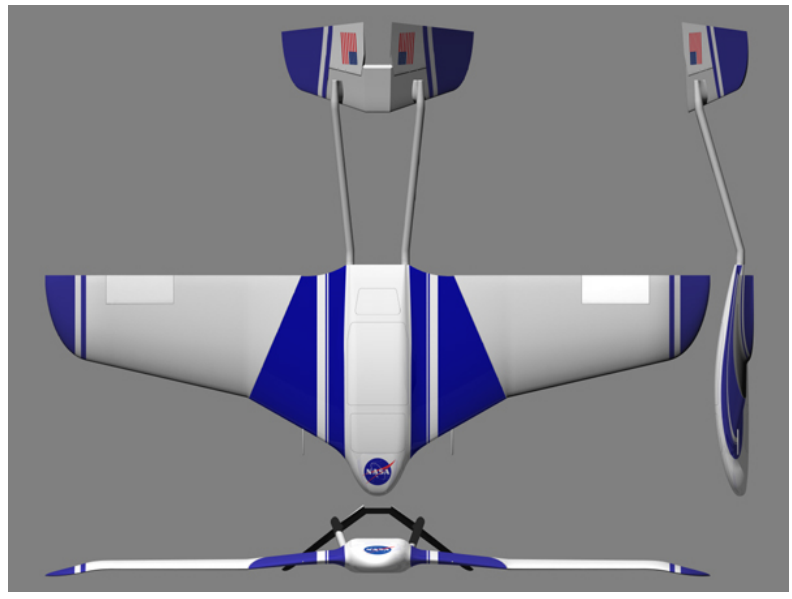

Figure 6. Three view of final ARES airplane design.

\section{A. Special Design Considerations}

Atmospheric density near the Martian surface is roughly equivalent to an altitude of 100,000 feet on Earth. With such a thin atmosphere, generating enough lift to support the airplane weight is difficult, despite the lower gravity on Mars. The atmospheric density and composition also cause difficulties generating thrust by conventional means. Most Earth airplanes use air-breathing propulsion systems, relying on oxygen $\left(\mathrm{O}_{2}\right)$ from incoming air as an oxidizer to release energy stored in the on-board fuel. This approach is not viable in the mainly carbon dioxide $\left(\mathrm{CO}_{2}\right)$ Martian atmosphere. There are significant challenges associated with just getting the airplane to Mars as well. The geometric arrangement best suited for efficient, stable atmospheric flight is much different from that best suited for launch and atmospheric entry. Efficient packaging of the aircraft is critical to provide sufficient wing area (lift capability) within the geometric constraints of the launch and entry vehicles.

Although flying an airplane on Mars is certainly an exciting aeronautical event, from a mission perspective the airplane is simply a platform with which to accomplish the science objectives. Therefore, the general design philosophy that was adopted for the ARES airplane was to look for the simplest, most robust means to meet the science requirements. Minimizing the risk, complexity, and cost of the airplane system was a primary driver in design decisions. The fact that the ARES mission was part of a competitive selection process also influenced design decisions. To have a successful proposal the airplane design needed to not only meet the mission requirements but also be robust and practical from the perspective of the proposal evaluators.

\section{B. Concept Trade Studies}

\section{Aeroshell Packaging Approach}

The ARES airplane was required to fit within a Viking derivative aeroshell shape, shown in Fig. 7. This shape is not ideal in terms of maximizing airplane size and performance, but was selected because of aeroshell design heritage. Packaging in the aeroshell is complicated by a parachute canister, which extends through the middle of the aeroshell interior and six separation fittings around the perimeter, i.e., where the backshell and heat shield of the aeroshell attach. Possible packaging approaches considered included: none, non-rigid wing, inflatable wing, telescoping structure, and folding structure. 


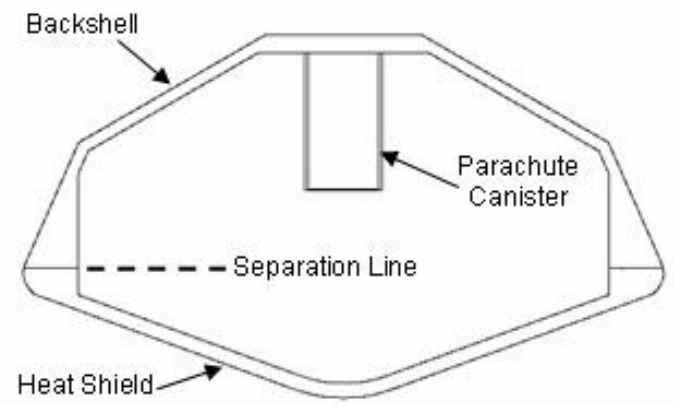

Figure 7. ARES aeroshell shape, Viking derivative with stretched backshell.

The lowest risk packaging approach is to simply make the airplane small enough to fit inside the aeroshell in the flight configuration. Analysis of this approach determined that the resulting wing area would limit the maximum airplane mass to values too low to meet the ARES science payload and range requirements. Using a non-rigid or inflatable wing takes most advantage of the available aeroshell volume. The main issue with these concepts was the additional risk entailed over a conventional structure. Of particular concern was the performance of flexible materials after being exposed to a cold environment for the approximately one year transit to Mars. A conventional rigid structure can be built with space-qualified materials. A number of past space systems have used telescoping mechanisms. There is a history, however, of problems with these mechanisms. Spring-loaded folds were considered the simplest, lowest risk packaging approach. Since there is still risk involved in the aircraft unfolding, minimizing the number of folds was a design objective during other design trade studies.

\section{Propulsion}

Low atmospheric density and the lack of appreciable amounts of atmospheric $\mathrm{O}_{2}$ complicate propulsion for a Mars airplane and lead to consideration of unconventional (from an Earth airplane perspective) propulsion options. Propulsion options considered for the ARES airplane included: no propulsion (glider), rocket (liquid and solid), and propeller (driven by various power sources). A glider was attractive because of the mass, cost, and risk reduction associated with eliminating the propulsion system. However, the performance requirements dictated by the ARES science objectives could not be met with a glider. A number of propeller-based propulsion systems were considered. A propeller can be an efficient means of generating thrust and has been the propulsion choice for most past Mars airplane concepts and low-speed, high-altitude Earth aircraft. Unfortunately, selection of a propeller-based system would have added significantly to the development cost and risk because of the immaturity of the technologies involved. Rocket propulsion was deemed the lowest risk option (excluding the glider option) because of its space heritage and robust thrust generation. A liquid rocket propulsion system was ultimately selected for the ARES airplane design because it was the lowest risk, lowest cost system which enabled the science objectives to be met. If the primary design focus had been to maximize aircraft performance, and funding was allocated accordingly for propulsion system development, the rocket system would likely not have been the preferred concept.

\section{Tail Arrangement}

Once the packaging and propulsion trade studies were completed, various aircraft layouts were investigated. Of particular importance was finding a tail arrangement which could provide acceptable airplane stability and control while meeting aeroshell packaging constraints. Early in the concept exploration phase some consideration was given to a canard-wing arrangement but this approach was discarded for a number of reasons. Considerable attention and analysis was applied to four other possible arrangements before arriving at the final "inverted V-tail" configuration. Ideas investigated included: tailless (flying wing), conventional tail, wingtip tails, and split tails. Versions of these concepts are shown in Fig. 8. 


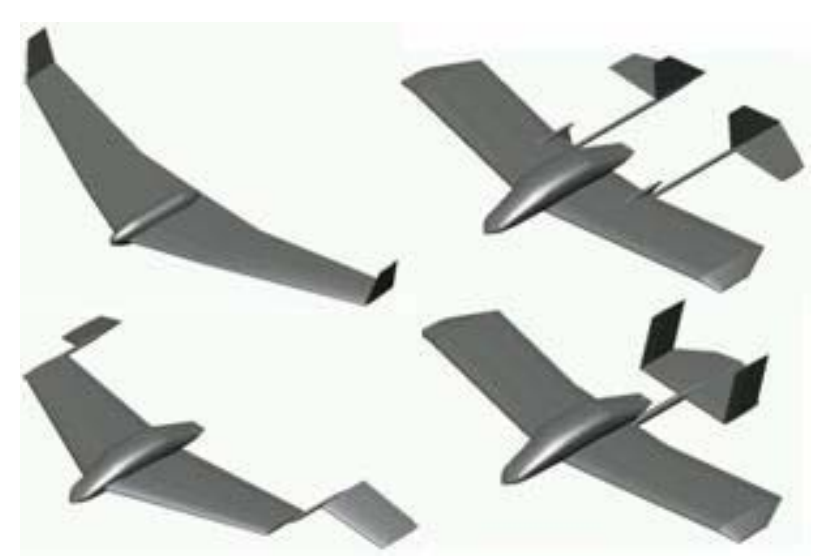

Figure 8. Some candidate ARES airplane configurations.

An example of the type of comparative, quantitative analysis performed is contained in Table 4. Ultimately, predicted aerodynamic performance and stability and control were not the primary discriminators among the concepts. Many other factors, which were considered through qualitative evaluation, influenced the concept selection.

Table 4. Example Concept Comparison

\begin{tabular}{|l|c|c|c|}
\hline Tail Arrangement & Tip & Split & Center \\
\hline HT Area, cm2 & 9780 & 9780 & 12,280 \\
\hline Aerodynamic Center, cm & 141 & 130 & 132 \\
\hline Analyzed CG, cm & 136 & 125 & 126 \\
\hline Static Margin & $5.0 \%$ & $5.2 \%$ & $5.2 \%$ \\
\hline HT Volume Coefficient & 0.24 & 0.37 & 0.37 \\
\hline \multicolumn{2}{|c|}{ Trim @ $\mathrm{C}_{\mathrm{L}}=0.7$} \\
\hline Delta flap, deg & -17.5 & -11.1 & -7.0 \\
\hline Wing max section $\mathrm{C}_{\mathrm{I}}$ & 0.84 & 0.87 & 0.87 \\
\hline Tail max negative $\mathrm{C}_{\mathrm{I}}$ & -0.33 & -0.51 & -0.43 \\
\hline Total induced $\mathrm{C}_{\mathrm{D}}$ & 0.0412 & 0.0354 & 0.0346 \\
\hline
\end{tabular}

The susceptibility of a tailless design to adverse flight motions initiated from unusual attitudes (as would be encountered at the onset of the ARES airplane deployment sequence) was the basis for eliminating the flying wing design from further consideration. Although the "conventional" tail arrangement allowed a large tail area, this concept had the highest number of folds (5). While promising from a performance standpoint, the wingtip tail design generated concern from a structural standpoint. This arrangement also had the least flexibility in possible wing planforms and folding schemes. Aerodynamic performance of the twin, "split tail" configuration was found to be similar to the conventional tail arrangement with one less fold required, implying lower deployment risk. Out of the four concepts shown in Fig. 8, the "split tail" arrangement was selected as the preferred concept. It was later observed that there was no compelling reason for the two tails to be completely independent. This observation led to consideration of an inverted V-tail arrangement requiring just three unfolding events. As shown in Fig. 9, the V-tail shape with deflected control surfaces fits well in the conical backshell of the aeroshell. Two booms, positioned to avoid interference with the parachute canister, are used to connect the tail to the fuselage. These tail booms are not subjected to the type of torsional loads present for the split tail or wingtip tail arrangements. The reduction in boom structural issues, improved aerodynamics, and fewer unfolding events made the inverted V-tail concept preferred over the initially selected split tail arrangement. 


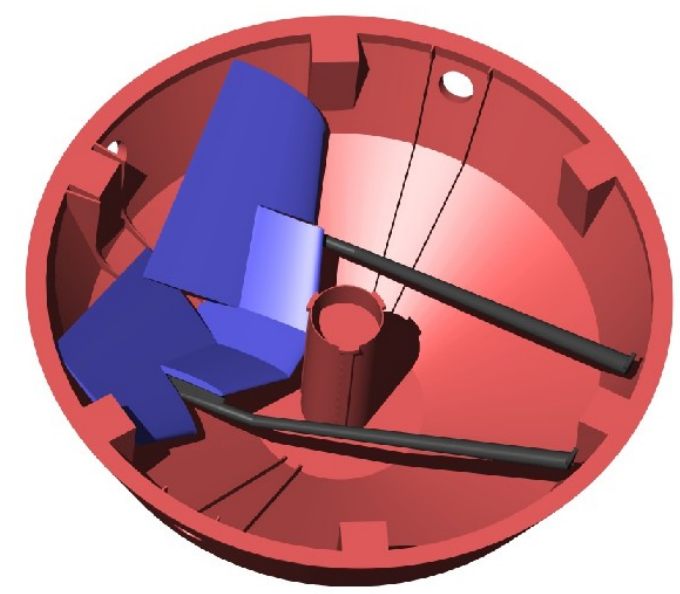

Figure 9. V-tail packaged in aeroshell backshell.

\section{Wing Geometry}

The folding of a rigid wing structure into the entry aeroshell presents a number of unique considerations in selection of a wing planform shape. There is a trade-off between wing area and aspect ratio that must be considered. For most airplanes wing area and aspect ratio can be selected somewhat independently, with aspect ratio usually a trade-off between aerodynamic performance and structural weight and wing area often dictated by takeoff or maneuver requirements. For the ARES airplane, fitting the wing into the circular aeroshell restricts the possible wing area-aspect ratio combinations. Possible planform shapes were explored extensively, and a spreadsheet-based geometry analysis routine was developed which permitted some geometry/folding optimization to be performed. Using this spreadsheet an investigation of the trade-off between wing area and aspect ratio was performed, the results of which are shown in Fig. 10. Although important to establish the limits and trade-offs between wing area and aspect ratio, the results by themselves do not point to an obvious planform choice. Selecting a large wing area, at the expense of aspect ratio, might permit a larger airplane mass capability. With the larger mass capability, the additional fuel carried could possibly offset the decrease in aerodynamic performance resulting from the lower aspect ratio. On the other hand, increasing aspect ratio would tend to decrease the amount of fuel, and therefore airplane mass, necessary to achieve a given range. Selecting the best combination of aspect ratio and wing area required an understanding of the performance trades as well as the geometry constraints. Based on the experience of team members, results from previous studies, and preliminary mission analysis, a baseline planform with an aspect ratio of 6 and wing area of $7.0 \mathrm{~m}^{2}$ was selected. For simplicity, most of the initial planform trade studies were conducted assuming the wing was folded in a cylinder, i.e., the decrease in aeroshell diameter with height was not included. Accommodating the real 3-D packaging constraints involved a number of refinements leading to the final ARES airplane planform shape.

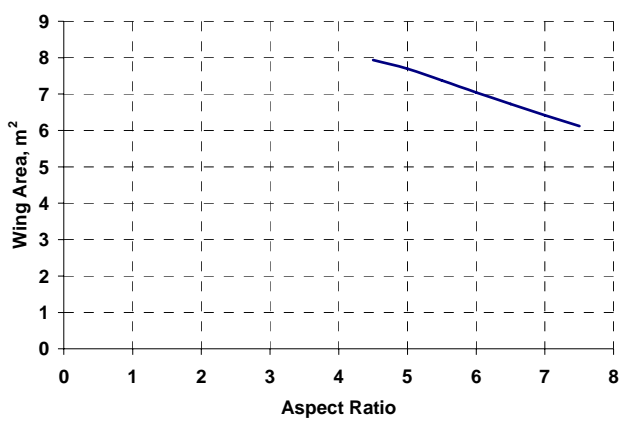

Figure 10. Variation of maximum wing area with aspect ratio.

\section{Summary}

The SACD performs mission and trade study analysis for NASA organizations and other customers spanning the full breadth of aerospace systems, from aviation to human space exploration. In mission analysis a number of alternative systems are typically developed and assessed relative to mission goals and objectives. This is done in 
order to determine the most favorable design approaches for further refinement. Trade studies illustrate the impact of design decisions and requirements on a system; allowing for informed selections among competing options. The results of trade studies are often used to iteratively refine the mission and system requirements and create a more balanced system given the best design and technology choices available. Mission and trade study analysis involves both physics-based (aerodynamics, propulsion, flight mechanics, and structures) and non-physics-based (cost, reliability, safety, and operations) disciplines. Each discipline's particular method of analysis is chosen as appropriate given the scope and level of fidelity required coupled with the availability of resources and time. Personnel resources can range from a single person to a large team consisting of individual discipline experts teamed with systems analysts. All of the mission and trade study analyses at NASA Langley are conducted within an ISO9001 certified Langley Management System framework to assure quality of the methods and study output. The SACD's analysis methods and techniques have been highly commended in periodic formal peer reviews with experts from academia, industry, and other government agencies.

The best indicator of the quality of SACD mission and trade study analysis is the numerous requests for study collaboration and analysis methods. Examples of study requests include leading the systems analysis for such diverse projects as the Hyper-X Program, the future human Lunar Mission Scenarios study for NASA's Exploration Systems Mission Directorate (ESMD), and the Aerial Regional-scale Environment Survey of Mars (ARES) mission air vehicle. Examples of methods developed by Langley and in wide use include the FLight OPtimization System (FLOPS), which has a user community of over 200 organizations in 8 countries, and the spacecraft trajectory program POST (Program to Optimize Simulated Trajectories), which is used throughout the US.

While tools are important, the ability of the analysts to understand the problem, formulate a plan, acquire and learn new tools, modify existing tools as needed, and satisfy the customer's requirements within scope and time limitations, usually on concepts in which there is little prior experience, is the SACD's greatest asset. The missions for these systems encompass an incredibly broad range from aviation to space exploration, often-encompassing geometries, environments, and technologies in which there is little or no previous experience.

Two specific examples of analyses performed in just such unfamiliar territory were presented in this paper: the Lunar Mission Scenarios (LMS) study, and the Aerial Regional-scale Environment Survey (ARES) mission air vehicle study. The Lunar Mission Scenarios (LMS) study examined a series of individual scenarios and resulted in general trends being observed across scenarios, additional mission risks and system hazards being identified, and lunar system elements that reduce risk for future Mars missions being identified. The Aerial Regional-scale Environment Survey (ARES) study resulted in a re-evaluation of design elements for the unfamiliar Martian environment, experience in merging quantitative and qualitative analysis in a system that emphasized mission robustness over vehicle performance, and a specific vehicle design that contributed to the ARES mission being selected as a finalist in the 2007 Mars Scout competition.

These specific examples illustrate that it is possible to quantify complex systems and inform decision makers as to the multidisciplinary characters of those systems and the relative value of design or architecture choices. The SACD has demonstrated a track record over many years of both high quality and unbiased analyses, with fidelity appropriate for the resources and scope dictated by the individual study and customer needs. Because the SACD is agile and more flexible in its analysis approach than other organizations that specialize in narrowly defined, evolutionary concepts, the SACD is the organization of choice for the assessment of revolutionary mission and vehicle concepts.

\section{References}

${ }^{1}$ Shishko, R., “NASA Systems Engineering Handbook,” NASA SP 6105, 1995.

${ }^{2}$ Mazanek, D. D., Lepsch, R. A., and Saucillo, R. J., "Lunar Architecture Broad Trade Study Final Report," NASA Exploration Systems Mission Directorate , ESMD-RQ-0006 (Baseline), September, 2004.

${ }^{3}$ Levine, J.S., et al., "Science from a Mars Airplane: The Aerial Regional-scale Environmental Survey (ARES) of Mars," AIAA 2003-6576, 2003.

${ }^{4}$ Guynn, M. D., Croom, M. A., Smith, S. C., Parks, R. W., and Gelhausen, P. A., "Evolution of a Mars Airplane Concept for the ARES Mars Scout Mission,” AIAA 2003-6578, 2003. 